\title{
Discussion on the Training Mode of Computer Major in Colleges and Universities Under the Background of Big Data
}

\author{
Jian Peng
}

Jiangxi Vocational Technical College of Industry \& Trade, Nanchang, Jiangxi, 330038 3107000933@qq.com

\begin{abstract}
People have entered the era of big data, and in the era of big data, people can get the information is also explosive growth, but when people can get more data and information, people will be more difficult to process the information, so people should master the big data technology, use the big data technology to apply and process the big data, and in the current market, big data technology has become one of the criteria for testing talent, and big data technology is also a kind of computer technology, in the training of computer professionals in colleges and universities, the level of big data technology for students is also required, this paper mainly around the big data back. Research and discussion on the model of computer training in colleges and universities.
\end{abstract}

Keywords: Keywords big data; university; computer major; training model; discussion

\section{大数据背景下的高校计算机专业培养模式探讨}

\author{
彭健
}

江西工业贸易职业技术学院, 江西, 南昌, 330038

3107000933@qq.com

\section{摘要}

人们目前已然进入了大数据时代，而在大数据时代，人们所能够获取的信息也是爆炸式增长，但是当 人们所能够得到的数据和信息越多，人们就越难对这些数据的信息进行处理，因此人们也应该掌握大 数据技术，利用大数据技术对大数据进行应用和处理，而在当前市场上，大数据技术也成为了检验人 才的标准之一，而大数据技术也属于计算机技术的一种，在高校计算机专业人才培养中，对学生的大 数据技术水平也有所要求, 本文就主要围绕大数据背景下的高校计算机专业模培养模式进行研究和探 讨。

关键词: 大数据；高校；计算机专业；培养模式；探讨

\section{1. 大数据技术对高校计算机专业的影响}

我国当前市场上非常缺乏大数据专业人才, 一方面 是由于大数据技术的发展过快, 另一方面, 是由于之前 人才培养的主要平台都还没有意识到大数据技术的重 要性, 但是当下高校已经注意到了大数据技术的崛起, 因此也开始有越来越多的高校申请开设数据科学与计 算专业, 而这个专业所招收的学生越来越多, 如果高校 加强对数据科学与计算专业的人才培养, 也能够为社会 提供更多的大数据技术应用人才, 但是想要达成这一目 标的前提是, 改革高校计算机专业教学, 适应大数据发
展的需求, 而除了大数据技术人才资源的迫切需求之 外, 计算机专业教学也因为大数据技术的发展受到了不 同程度的影响。

\section{1 对计算机专业课程体系的影响}

我国高校计算机专业人才培养模式已经趋近稳定, 并且较为成熟, 但是随着越来越多先进的计算机理念和 计算机技术出现, 使得计算机专业课程体系也要因此而 改变。而在高校对计算机专业的课程体系进行设置时, 就应该考虑到这些先进技术，例如大数据技术对计算机 专业产生的影响, 只要考虑到了这些影响因素, 才能够 


\section{2 对教学模式的影响}

计算机专业是走在社会前沿的专业, 是随着社会的 变化而变化的专业, 都有了先进的技术时, 计算机专业 课程体系就必须进行调整, 计算机专业对学生的能力培 养的基础是计算机软硬件编程, 但是目前纵观时代的发 展, 在计算机专业中应该加入对学生大数据分析和处理 能力的培养, 只有当学生同时具备计算机软硬件编程能 力和大数据应用能力时, 学生才成为了全面型计算机人 才, 而培养学生的大数据技能也是为了增强学生的就业 竞争力。

\section{表 1 大数据背景下计算机专业培养模式探讨}

\begin{tabular}{|c|c|c|}
\hline $\begin{array}{c}\text { 对计算机专业课程 } \\
\text { 体系的影响 }\end{array}$ & 对教学模式的影响 & $\begin{array}{c}\text { 对高校教师的影 } \\
\text { 响 }\end{array}$ \\
\hline $\begin{array}{l}\text { 我国高校计算机专 } \\
\text { 业人才培养模式已 } \\
\text { 经趋近稳定, 并且 } \\
\text { 较为成熟, 但是随 } \\
\text { 着越来越多先进的 } \\
\text { 计算机理念和计算 } \\
\text { 机技术出现, 使得 } \\
\text { 计算机专业课程体 } \\
\text { 系也要因 此而改 } \\
\text { 变。而在高校对计 } \\
\text { 算机专业的课程体 } \\
\text { 系进行设置时, 就 } \\
\text { 应该考虑到这些先 } \\
\text { 进技术, 例如大数 } \\
\text { 据技术对计算机专 } \\
\text { 业产生的影响, 只 } \\
\text { 要考虑到了这些影 } \\
\text { 响因素, 才能够真 } \\
\text { 正将计算机专业人 } \\
\text { 才培养做到位。 }\end{array}$ & $\begin{array}{l}\text { 计算机专业是走在 } \\
\text { 社会前沿的专业, } \\
\text { 是随着社会的变化 } \\
\text { 而变化的专业, 都 } \\
\text { 有了先进的技术 } \\
\text { 时, 计算机专业课 } \\
\text { 程体系就必须进行 } \\
\text { 调整, 计算机专业 } \\
\text { 对学生的能力培养 } \\
\text { 的基础是计算机软 } \\
\text { 硬件编程, 但是目 } \\
\text { 前纵观时代的发 } \\
\text { 展, 在计算机专业 } \\
\text { 中应该加入对学生 } \\
\text { 大数据分析和处理 } \\
\text { 能力的培养, 只有 } \\
\text { 当学生同时具备计 } \\
\text { 算机软硬件编程能 } \\
\text { 力和大数据应用能 } \\
\text { 力时, 学生才成为 } \\
\text { 了全面型计算机人 } \\
\text { 才, 而培养学生的 } \\
\text { 大数据技能也是为 } \\
\text { 了增强学生的就业 } \\
\text { 竞争力。 }\end{array}$ & $\begin{array}{l}\text { 高校计算机专业 } \\
\text { 课程体系改革对 } \\
\text { 教师也造成了不 } \\
\text { 同程度的影响, } \\
\text { 为了能够加强对 } \\
\text { 学生大数据技术 } \\
\text { 应用能力的培 } \\
\text { 养, 教师也必须 } \\
\text { 具备一定的大数 } \\
\text { 据 技术应用能 } \\
\text { 力, 而教师学习 } \\
\text { 大数据技术比学 } \\
\text { 生学习大数据技 } \\
\text { 术要更加容易, } \\
\text { 因为教师已经有 } \\
\text { 了较高水平的计 } \\
\text { 算机能力, 而学 } \\
\text { 校需要做的就是 } \\
\text { 为教师提供更多 } \\
\text { 学习和培训的机 } \\
\text { 会, 让教师能够 } \\
\text { 在培训的过程中 } \\
\text { 了解更多的大数 } \\
\text { 据技术, 并提升 } \\
\text { 自己的大数据技 } \\
\text { 术应用水平。 }\end{array}$ \\
\hline
\end{tabular}

\section{3 对高校教师的影响}

高校计算机专业课程体系改革对教师也造成了不 同程度的影响, 为了能够加强对学生大数据技术应用能 力的培养, 教师也必须具备一定的大数据技术应用能 力, 而教师学习大数据技术比学生学习大数据技术要更 加容易, 因为教师已经有了较高水平的计算机能力, 而 学校需要做的就是为教师提供更多学习和培训的机会, 让教师能够在培训的过程中了解更多的大数据技术, 并

\section{2. 大数据背景下计算机专业培养模式探讨}

\section{表 2 大数据背景下计算机专业培养模式探讨}

\begin{tabular}{|c|c|c|}
\hline $\begin{array}{c}\text { 明确课程培养的 } \\
\text { 目标 }\end{array}$ & $\begin{array}{l}\text { 加强校企合作, } \\
\text { 提高学生的大数 } \\
\text { 据实践能力 }\end{array}$ & $\begin{array}{c}\text { 加强大数据实验平台 } \\
\text { 建设 }\end{array}$ \\
\hline $\begin{array}{l}\text { 计算机专业和其 } \\
\text { 他专业的差异就 } \\
\text { 在于计算机专业 } \\
\text { 的教学目标和人 } \\
\text { 才培养目标一直 } \\
\text { 在不断变化, 而 } \\
\text { 这主要是由于时 } \\
\text { 代对计算机专业 } \\
\text { 人才的要求在不 } \\
\text { 断变化, 而高校 } \\
\text { 的培养目的一直 } \\
\text { 都是为了为社会 } \\
\text { 输送更多符合社 } \\
\text { 会需求, 满足社 } \\
\text { 会发展的人。格。 }\end{array}$ & $\begin{array}{c}\text { 实践能够有效提 } \\
\text { 升学生的计算机 } \\
\text { 能力, 因为通过 } \\
\text { 实践学生能够更 } \\
\text { 加深入的了解理 } \\
\text { 论并掌握理论。 } \\
\text { 因此教师应该给 } \\
\text { 予学生更多的空 } \\
\text { 间, 让学生能够 } \\
\text { 在实际操作的过 } \\
\text { 程中学习理论, } \\
\text { 又在学习理论的 } \\
\text { 过程中进行实践 } \\
\text { 操作。 }\end{array}$ & $\begin{array}{l}\text { 高校也应该加强对大 } \\
\text { 数据技术实验平台的 } \\
\text { 建设, 学生是无法在 } \\
\text { 计算机实验室中进行 } \\
\text { 大数据技术应用操作 } \\
\text { 的, 因为大数据技术 } \\
\text { 与专业计算机技术还 } \\
\text { 是存在差异的, 因此 } \\
\text { 高校应该为学生配备 } \\
\text { 专业的大数据实验 } \\
\text { 台, 让学生能够在课 } \\
\text { 后也利用大数据实验 } \\
\text { 平台加强自己对大数 } \\
\text { 据技术的掌握, 而大 } \\
\text { 数据实验平台不仅能 } \\
\text { 够为学生提供服务, } \\
\text { 也能够为教师提供服 } \\
\text { 务。 }\end{array}$ \\
\hline
\end{tabular}

\section{1 明确课程培养的目标}

计算机专业和其他专业的差异就在于计算机专业 的教学目标和人才培养目标一直在不断变化, 而这主要 是由于时代对计算机专业人才的要求在不断变化, 而高 校的培养目的一直都是为了为社会输送更多符合社会 需求, 满足社会发展的人才。而之所以要求计算机专业 的学生掌握大数据技术, 也是因为时代发展需求。同时 也因为大数据技术是建立在计算机技术的基础之上的, 学生能够在学习计算机技术的过程中, 了解到大数据技 术, 也能够在掌握大数据技术的过程中巩固计算机技 术, 而在对学生的大数据技术培养的过程中, 教师也必 须要明确大数据技术的培养方向分为两种, 大数据应用 和大数据分析和处理。而大数据应用更适合开设专门的 专业, 大数据分析和处理则可以作为课程纳入到计算机 专业中。

\section{2 加强校企合作, 提高学生的大数据实践能 力}

实践能够有效提升学生的计算机能力, 因为通过实 践学生能够更加深入的了解理论并掌握理论。因此教师 应该给予学生更多的空间, 让学生能够在实际操作的过 程中学习理论, 又在学习理论的过程中进行实践操作。 
但是因为现今有关于大数据技术的教学还不够成熟, 因 此也没能建立起完善而健全的教学体系。在这种情况 下，想要更好的培养学生的大数据技术应用能力是存在 一定难度的, 而培养学生大数据技术应用能力的主要难 点在于, 学生难以在学校中进行大数据技术应用的实践 操作, 而为了能够达成人才培养目标, 学校应该加强和 企业之间的合作, 让学生进入企业进行实践操作, 并加 强对大数据技术应用的掌握, 而对于企业而言, 企业也 能够获取到更多的人才资源。

\section{3 加强大数据实验平台建设}

高校也应该加强对大数据技术实验平台的建设, 学 生是无法在计算机实验室中进行大数据技术应用操作 的, 因为大数据技术与专业计算机技术还是存在差异 的, 因此高校应该为学生配备专业的大数据实验平台, 让学生能够在课后也利用大数据实验平台加强自己对 大数据技术的掌握, 而大数据实验平台不仅能够为学生 提供服务, 也能够为教师提供服务, 学校可以将大数据 实验平台设为公共开放的平台, 实现全校共享。

\section{3. 大数据背景下计算机专业人才培养的基本 原则}

大数据行业正全面展开, 为了培养具有较强计算机 技术实际应用能力、知识创新能力和大数据管理与分析 能力的高级应用型工程技术人才, 以适应大数据时代的 需要, 从大数据角度培养计算机专业人才应遵循以下基 本原则。

\section{1 多学科协同原则}

计算机专业是一个以系统为导向、注重应用、软硬 兼备的多向性专业。计算机科学涵盖了广泛的课程, 并 与其他学科密切相关。于此, 大数据背景下的新型大数 据处理与分析对计算机专业人员提出了新的要求。因 此, 在大数据时代, 计算机专业人才的培养应注重多学 科的协同创新与发展, 重视跨学科基础知识和跨学科学 习能力的培养。

\section{2 校企协同创新原则}

大数据是基于互联网、物联网和云计算的产物, 计 算机专业人员在具备计算机软硬件系统分析和开发能 力基础的同时, 还应掌握大数据的采集、存储、管理与 应用分析等能力。然而, 在各高校大数据计算机的人才 培养还处于摸索阶段, 尚未形成相应的体系。大数据处 理来是一项交叉学科的系统工作, 对于应用性和实践性 有较高的要求。为此大数据人才的培养需要各企业的介 入, 以结合高校大数据研究机构与企业计算机人才培养
项目, 可以为学生提供更生动的大数据管理和应用分析 案例和实践平台, 来提高计算机专业人才分析大数据的 能力。

\section{3 以数据为中心原则}

计算机行业在大数据时代真正发展成了信息行业, 对于大数据的技术处理能力, 计算机专业人才也应该充 分掌握。对于大数据处理技术的定义是指在各类的海量 数据中, 能够迅速从中获得具有价值的信息。当下以数 据为核心是软件发展的重要方向, 为此, 各高校计算机 专业应以数据为中心, 完善课程体系、改善教学内容, 强化对于大数据分析处理能力的应用实践。

\section{4. 结语}

总而言之，计算机人才已经成为我国目前必不可少 了人才种类之一，而大数据技术的出现，又为我国计算 机人才的培养提供了另一条方向, 而为了能够充分的发 挥出高校人才培养的作用, 高校也应该加强对学生的大 数据技术应用能力的提升, 使学生能够满足社会的需 求。而为了能够达成这一目的, 高校必须改革计算机专 业课程体系, 在计算机专业课程体系中加入大数据技术 相关课程。在如今竞争激烈的人才市场上, 加强对学生 进行计算机信息技术的培养和提升也是在加强学生的 就业竞争力。

\section{REFERENCES}

[1] Wang Zhong, Shi Peibei. Research on Data Science and the Construction of Big Data Technology Specialty [J]. Journal of Anqing Normal University (Natural Science Edition).2019(01)

[2] Hao Jianmin. A study on improving the management level of computer practice teaching in applied undergraduate colleges in big data era $[\mathrm{J}]$. Technology horizon. 2018(33)

[3] An exposition of computer information processing methods in the era of "big data "[ J]. Computer knowledge and technology. 2016(34)

[4] Tang Jing. Discussion on the Innovation of Public Computer Teaching Reform in Higher Vocational Colleges -- From the Perspective of Intersubjectivity Theory [J]. Human resource development. 2017(02)

[5] How to deepen the reform of computer teaching to improve students'practical application ability [J]. Dong Fang. Wisdom. 2015(01) 
[6] Hu Rong. Research on computer teaching in colleges and universities based on the background of big data [J ]. Science and technology outlook. 2016(24)

[7] Liu Zhengbin. Training Model of Information Management and Information System Specialty in the Background of Big Data [J].] Journal of Jiamusi Vocational College. 2019(09)

[8] Xu Shuangyi. Innovating the training mode of music performance specialty and cultivating compound applied talents [J].] Northern music. 2017(15)

[9] Yang Min, Cai Xiaohong. Research on current pre-school training model — focusing on the five-year pre-school major [J].] Technology Information. 2008(12)

[10] Liu Wei. Discussion on the Training Model of University Computer Specialty under the Background of Big Data [J].] Technology Information. 2019(13)

[11] Zhang Hui. Study on the Transformation of the Training Mode of Accounting Specialty in Colleges and Universities under the Trend of Financial Sharing [J].] Modern economic information. 2019(05)

[12] Ye Tianchi, Luo Zhongbao, Chen Li. "34. Study on the Training Mode of Automation Specialty in Secondary Vocational Education [J].] Journal of Jilin Normal University of Engineering and Technology. 2019(05)

[13] Cheng Ping, Li Jing. Study on the Training Mode of Double Degree and Minor Second Major in Undergraduate Education [J].] Science, education and literature (last ten days). 2019(12)

[14] Lan Ling, Zhao Wutong. Research on Innovation of Training Mode of Employment-oriented Human Resource Management Specialty [J].] Economist. 2017(10)

[15] Xu Huashan, Wang Lijin, Mu Linlin, Xie Xingli, Wang Wenjuan. Reform and Exploration of Training Mode of Applied Psychiatry Specialty [J].] Journal of Bengbu Medical College. 2016(07) 